\title{
Recycling of Oily Sludge as a Roadbed Material Utilizing Phosphogypsum-Based Cementitious Materials
}

\author{
Wei Xiao $(\mathbb{D}$, Xiao Yao $\mathbb{D}$, and Fuyang Zhang \\ College of Materials Science and Engineering, Nanjing Tech University, Nanjing 210009, China \\ Correspondence should be addressed to Xiao Yao; htmpaper@sina.com
}

Received 15 February 2019; Revised 30 April 2019; Accepted 7 May 2019; Published 23 May 2019

Academic Editor: Arnaud Perrot

Copyright (c) 2019 Wei Xiao et al. This is an open access article distributed under the Creative Commons Attribution License, which permits unrestricted use, distribution, and reproduction in any medium, provided the original work is properly cited.

\begin{abstract}
Oily sludge is a hazardous waste containing emulsified petroleum hydrocarbons, water, heavy metals, and solid particles. The objective of this work is to employ solidification/stabilization $(\mathrm{S} / \mathrm{S})$ techniques to utilize oily sludge as a roadbed material with ordinary Portland cement (OPC), fly ash (FA), and silica fume (SF) as binders and phosphogypsum (PG) as a stabilizer. The efficacy of the S/S process is assessed mainly through an unconfined compressive strength (UCS) test and a toxicity leaching test. Road performance, including water stability, freeze-thaw resistance, and volume stability, is also tested on the solidified samples. The mineralogical compositions, microstructures, and pore structure are characterized through X-ray diffractometry (XRD), scanning electron microscopy (SEM), and mercury intrusion porosimetry (MIP). The results show that the addition of $20 \%$ binders (OPC:FA:SF $=1: 0.7: 0.8$ ) in combination with phosphogypsum to the oily sludge not only increases the 28-day compressive strength of the solidified samples and remarkably decreases the release of heavy metals but also refines the pore structure and compacts the microstructure. The solidified body had sufficient strength and good water stability performance, freeze-thaw resistance, and volumetric stability. This solidification/stabilization (S/S) process, which combines oily sludge treatment and phosphogypsum resource utilization, significantly enhances environmental protection and renders the solidified product economically profitable.
\end{abstract}

\section{Introduction}

In recent years, crude oil production has continued to grow. Crude oil transportation and collection inevitably produce a large amount of oily sludge at the bottom of oil storage tanks [1]. In the Chinese petrochemical industry, over 800,000 tons of tank bottom sludge and pool bottom sludge is produced each year. Among them, the Dagang oilfield produces approximately 150,000 tons of oily sludge per year, and the Shengli oilfield produces more than 100,000 tons. Oily sludge contains large amounts of crude oil, inorganic salts, heavy metal ions, polycyclic aromatic hydrocarbons (PAHs), and other toxic substances, which pollute the soil, surface, and groundwater [2]. Thus, the disposal of tank oily sludge is a significant concern for the petroleum industry.

During recent years, several methods for oily sludge treatment have been developed, such as land farming, incineration, and solidification/stabilization. Many methods are not economical or practical and are difficult to apply universally [3]. The incorporation of oily sludge in a concrete mixture can provide an alternative treatment for this hazardous waste, providing both economic and environmental benefits [4]. Solidification/stabilization (S/S) is an effective and low-cost method that can minimize the impacts of these wastes on the environment.

Solidification/stabilization (S/S) methods basically involve the addition of cementitious binders to encapsulate the contaminants in a closed inert space by a physicochemical method, an approach which results in many excellent qualities, including mechanical properties antisoaking, antileaching, and antidrying properties [5]. The cement-based $\mathrm{S} / \mathrm{S}$ technique has been used worldwide for the solidification of contaminated soil [6]. Mohebbi used 20\% cement and 30\% modified clay to solidify cresol-contaminated soil. The results showed that adding 20\%-30\% Portland cement in combination with $15 \%-30 \%$ modified bentonite to contaminated 
soil increased the strength of S/S blocks and lowered the concentration of cresol in the leachate [7]. Mater used cement, clay, and lime to immobilize the recalcitrant and hazardous constituents of oily sludge-contaminated soil. The results showed that clay-lime S/S followed by Portland cement was effective to prevent contaminant leaching, and the solidified blocks were safe enough to be used as roadbeds [8]. Kogbara et al. used Portland cement, pulverized fuel ash, ground granulated blast furnace slag, and hydrated lime to solidify contaminated soil. The results demonstrated that adding a $20 \%$ dose of the other three binders satisfied the strength criteria and the stringent leaching criteria for most management scenarios [9].

In addition to the use of cement-based cementitious materials for waste treatment, phosphogypsum-based cementitious materials can also be used in waste treatment. Ding et al. used PG and cement to solidify dredged clays with high water content; the results showed that the unconfined compressive strength of solidified soils increases remarkably with the addition of cement and PG [10]. Rao and Asha used fly ash pozzolanic for controlling fluoride released from PG, and the results showed that fly ash, sand, lime, and PG slurries reduced the fluoride formation [11]. Li et al. used PG and fly ash to solidify drilling waste slurries; the results showed that the mixture had increased capacity for adsorption, and its compressive strength reached $2.6 \mathrm{MPa}$ [12]. Few studies have investigated using modified bentonites as stabilizers and cement as a binder to treat waste-oilcontaminated soil and sewage. The application of phosphogypsum material to the $\mathrm{S} / \mathrm{S}$ of oily sludge is also rare in the literature.

The purpose of the present study is to investigate the possibility of using phosphogypsum-based cementitious materials, including ordinary Portland cement (OPC), fly ash (FA), and silica fume (SF) as binders and phosphogypsum (PG) as a stabilizer to immobilize oily sludge. To characterize the oily sludge solidified product as a roadbed material, performance evaluation tests were performed, including unconfined compressive strength (UCS), water stability, freeze-thaw cycle, and expansion and leaching tests. $\mathrm{X}$-ray diffractometry (XRD), scanning electron microscopy (SEM), and mercury intrusion porosimetry (MIP) were used to characterize the mineralogical compositions, microstructures, and pore structure. This work presents the geotechnical results obtained in the S/S treatment of oily sludge. It represents a new way to utilize the resource of oily sludge in several engineering applications, which transforms oily sludge into a high-value product.

\section{Materials and Methods}

2.1. Materials. The oily sludge (OS) obtained from the Jiangsu Oilfield in China was composed of $25.70 \%$ oilsoluble component, $54.28 \%$ moisture, and $20.02 \%$ solids, as shown in Table 1 . The oil-soluble component was measured according to international standard ISO 9029-1990 [13], and the water content was measured using the ASTM D1744 method [14]. The solids content was calculated based on the water- and oil-soluble component content in the OS.
TABLE 1: Physical properties and heavy metal concentration of oily sludge.

\begin{tabular}{|c|c|c|c|c|c|c|}
\hline Parameters & & & & & Values & \\
\hline $\begin{array}{l}\text { Oil-soluble } \\
\text { component (wt. \%) }\end{array}$ & & & & & 25.70 & \\
\hline Moisture content (\%) & & & & & 54.28 & \\
\hline Solid content (\%) & & & & & 20.02 & \\
\hline $\mathrm{pH}$ & & & & & 8.24 & \\
\hline Heavy metals & $\mathrm{Ba}$ & $\mathrm{Cu}$ & $\mathrm{Zn}$ & Gr & $\mathrm{Ni}$ & $\mathrm{Pb}$ \\
\hline Content $(\mathrm{mg} / \mathrm{L})^{\mathrm{a}}$ & 1.562 & 0.825 & 0.670 & 0.282 & 0.136 & 0.333 \\
\hline
\end{tabular}

${ }^{\mathrm{a}}$ Concentration of heavy metals $(\mathrm{mg} / \mathrm{L})$.

The concentration of heavy metals in the oily sludge is also listed in Table 1, which shows that the main heavy metals were barium $(\mathrm{Ba})$, copper $(\mathrm{Cu})$, zinc $(\mathrm{Zn})$, chromium $(\mathrm{Cr})$, nickel $(\mathrm{Ni})$, and lead $(\mathrm{Pb})$. The chemical properties of the oily sludge are displayed in Table 2. The phosphogypsum (PG) was supplied by Mianzu of Sichuan (China). The physical properties and chemical composition of the PG were tested, and the results are shown in Table 3. Figure 1 shows the XRD pattern of the PG, which shows that its primary mineralogical composition is $\mathrm{CaSO}_{4} \cdot 2 \mathrm{H}_{2} \mathrm{O}$. The micromorphology of phosphogypsum is also displayed in Figure 1. Plate-like crystals were observed in the PG sample. The binders (OFS) used for $\mathrm{S} / \mathrm{S}$ treatment included ordinary Portland cement (OPC), fly ash (FA), and silica fume (SF). Their physical properties and chemical compositions are listed in Tables 3 and 4 , respectively.

\subsection{Experimental Methods}

2.2.1. Sample Preparation. All the samples were prepared by mixing OS, PG, and binders in a mortar mixer. First, certain amounts of OS and PG were weighed, and different proportions of OS and PG were added to the mortar mixer. The mass ratios of PG to oily sludge were $1: 1,3: 1$, and $5: 1$. The binders (OFS) were composed of ordinary Portland cement (OPC), fly ash (FA), and silica fume (SF). The samples were denoted as P1, P2, P3, P4, P5, and P6. The mix proportions of samples are listed in Table 5. Second, binder materials were mixed together in the appropriate proportions, and distilled water was added to form a concrete; further mixing continued until the mix was homogenous. The dose of the binders was $20 \%$ by total mass in a single sample.

The prepared mixture was placed into cylindrical molds $50 \mathrm{~mm}$ in diameter and $50 \mathrm{~mm}$ in height for extrusion forming. Using jacks to compact the samples in the mold, defects such as honeycomb, pores, pits, and others were removed. The molds were sealed with plastic wrap and cured for $24 \mathrm{~h}$. Next, after removing the plastic wrap and removing the samples from the molds, they were stored at $98 \%$ relative humidity and $20 \pm 2^{\circ} \mathrm{C}$ for an additional period of 28 days for curing. The sample preparation flow diagram is shown in Figure 2.

\subsubsection{Road Performance Evaluation}

(1) Unconfined Compressive Strength Tests. Unconfined compressive strength (UCS) is an important road 
TABLE 2: Chemical composition of dried oily sludge.

\begin{tabular}{lcccccccc}
\hline Materials & $\mathrm{SiO}_{2}$ & $\mathrm{CaO}$ & $\mathrm{SO}_{3}$ & $\mathrm{Al}_{2} \mathrm{O}_{3}$ & $\mathrm{Fe}_{2} \mathrm{O}_{3}$ & $\mathrm{MgO}$ & $\mathrm{Na}_{2} \mathrm{O}$ & $\mathrm{LOI}$ \\
\hline Content (\%) & 7.83 & 3.74 & 3.41 & 4.23 & 10.14 & 0.58 & 2.41 & 66.21
\end{tabular}

LOI: loss on ignition at $1000^{\circ} \mathrm{C}$.

TABLE 3: Physical properties of materials.

\begin{tabular}{lcccc}
\hline Constituent/parameter & FA & OPC & PG & SF \\
\hline Appearance & Powder & Powder & Powder & Powder \\
Color & Grey & Grey & Grey \\
Specific gravity $\left(\mathrm{g} / \mathrm{cm}^{3)}\right.$ & 2.35 & 2.22 & 3.14 & 2.20 \\
Specific surface area $\left(\mathrm{m}^{2} / \mathrm{kg}\right)$ & 550 & 486 & 443 & 12000 \\
\hline
\end{tabular}

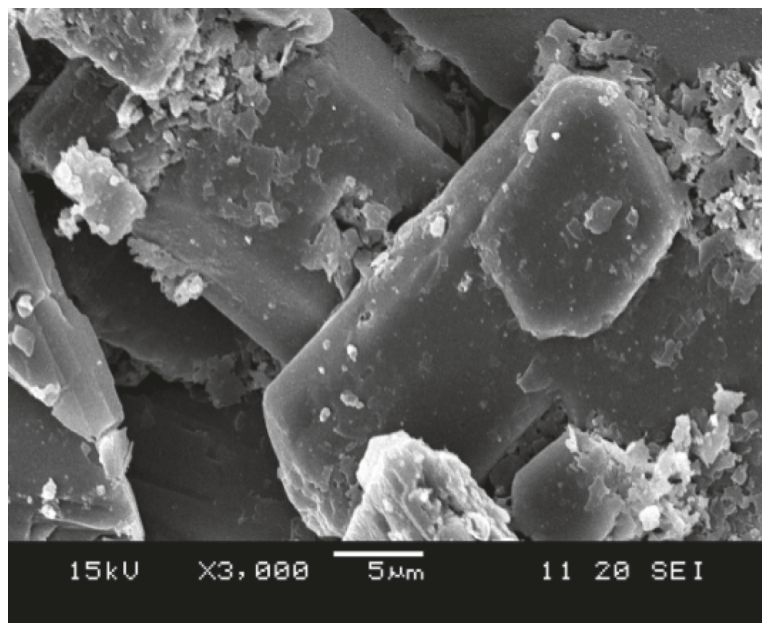

(a)

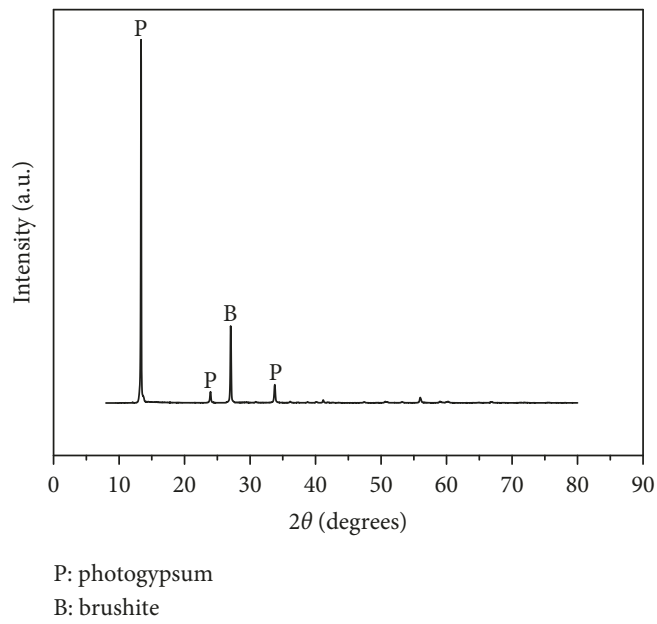

(b)

FIgURE 1: SEM micromorphology (a) and XRD pattern (b) of PG.

TABle 4: Chemical compositions of materials (wt. \%).

\begin{tabular}{lccccccccccc}
\hline Precursors & $\mathrm{SiO}_{2}$ & $\mathrm{CaO}$ & $\mathrm{SO}_{3}$ & $\mathrm{Al}_{2} \mathrm{O}_{3}$ & $\mathrm{Fe}_{2} \mathrm{O}_{3}$ & $\mathrm{Mg}_{2} \mathrm{O}$ & $\mathrm{Na}_{2} \mathrm{O}$ & $\mathrm{TiO}_{2}$ & $\mathrm{P}_{2} \mathrm{O}_{5}$ & $\mathrm{MnO}^{2}$ \\
\hline PG & 4.65 & 30.85 & 31.85 & 4.20 & - & 0.24 & 0.32 & 0.20 & 3.22 & - \\
OPC & 27.21 & 53.44 & 2.38 & 6.49 & 4.43 & 1.69 & 2.09 & - & - & - \\
FA & 50.01 & 5.61 & 0.58 & 32.61 & 4.44 & 0.98 & 0.59 & 1.06 & 0.27 & 0.07 \\
SF & 91.34 & 1.45 & 0.31 & 1.25 & 1.32 & 1.14 & 1.02 & - & - & - \\
\hline
\end{tabular}

LOI: loss on ignition at $1000^{\circ} \mathrm{C}$.

Table 5: Mix proportions of the samples.

\begin{tabular}{|c|c|c|c|c|c|c|c|}
\hline \multirow{2}{*}{ Sample } & \multirow{2}{*}{ OS (g) } & \multirow{2}{*}{ PG (g) } & \multicolumn{3}{|c|}{ Binders $(\mathrm{g})$} & \multirow{2}{*}{ Added water (g) } & \multirow{2}{*}{ Total water $(\mathrm{g})$} \\
\hline & & & OPC & FA & SF & & \\
\hline $\mathrm{P} 1$ & 84.0 & 84.0 & 16.8 & 11.8 & 13.4 & 42.0 & 84.0 \\
\hline $\mathrm{P} 2$ & 42.0 & 126.0 & 16.8 & 11.8 & 13.4 & 63.0 & 84.0 \\
\hline P3 & 28.0 & 140.0 & 16.8 & 11.8 & 13.4 & 70.0 & 84.0 \\
\hline $\mathrm{P} 4$ & 84.0 & 84.0 & 42.0 & - & - & 42.0 & 84.0 \\
\hline P5 & 42.0 & 126.0 & 42.0 & - & - & 63.0 & 84.0 \\
\hline P6 & 28.0 & 140.0 & 42.0 & - & - & 70.0 & 84.0 \\
\hline
\end{tabular}

performance index which can indicate a sample's potential for meeting the road standard (JTG E51-2009) [15]. The effects of S/S treatment were assessed by determining the UCS according to ASTM D2166 [16]. The compressive strength was tested using a Hualong WHY-200 machine with a loading rate of $1 \mathrm{~mm} / \mathrm{min}$. The test samples were cured for 7, 14, and 28 days. The average value for a group of six samples was calculated. 


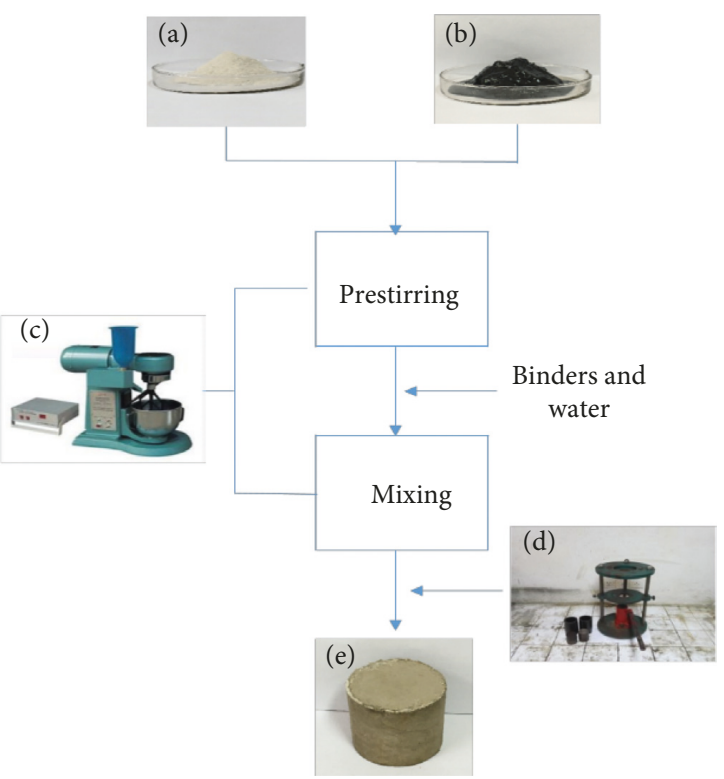

FIGURE 2: Sample preparation process: (a) PG material; (b) OS material; (c) mixer; (d) molds; (e) sample.

(2) Water Stability Tests. Water stability of the cured sample was tested by a simple method according to JTJ 051-1993 [17]: first, the sample $(\Phi 50 \mathrm{~mm} \times 50 \mathrm{~mm})$ which had been cured for 28 days was placed in an electronic balance, and the unconfined compressive strength $R_{0}$ was measured. Then, the other samples were placed in water at $20 \pm 2^{\circ} \mathrm{C}$ for the water saturation test. At 1, 3, 5, and 7 days, the test samples were removed, and after wiping off the surface moisture with a clean, dry rag, the samples were measured. Using the samples' unconfined compressive strength $R_{\mathrm{n}}$, the water stability coefficient $P$ was calculated according to

$$
P=\frac{R_{\mathrm{n}}}{R_{0}} .
$$

(3) Freeze-Thaw Cycle Tests. They were performed by standard methods described in JTG E51-2009. The test was carried out by using the specimens $(\Phi 50 \mathrm{~mm} \times 50 \mathrm{~mm})$ maintained for $5,10,15$, and 20 cycles of 28 days. First, a sample which had been cured for 27 days was placed in water at $20 \pm 2^{\circ} \mathrm{C}$ for $24 \mathrm{~h}$, then weighed to obtain $M_{0}$, and its unconfined compressive strength $R_{0}$ was measured. Next, the other samples were placed in a freeze-thaw box, stored at $-20^{\circ} \mathrm{C}$ for $16 \mathrm{~h}$, and then thawed in water at $20^{\circ} \mathrm{C}$ for $8 \mathrm{~h}$, which constitutes one freeze-thaw cycle. If the average mass loss rate of the samples was more than $5 \%$, the freeze-thaw cycle test was stopped and the samples were removed. The mass $M_{\mathrm{n}}$ and the unconfined compressive strength $R_{\mathrm{n}}$ were measured, and then the mass loss rate $W_{\mathrm{n}}$ and the unconfined compressive strength loss rate (BDR) were calculated by

$$
\begin{aligned}
W_{\mathrm{n}} & =\frac{M_{0}-M_{\mathrm{n}}}{M_{0}} \times 100, \\
\mathrm{BDR} & =\frac{R_{0}-R_{\mathrm{n}}}{R_{0}} \times 100 .
\end{aligned}
$$

(4) Expansion Tests. They were performed by standard methods described in GBT 50123-1999 [18]. First, the stirred sample was placed in a dilatometer, and then water was added until it covered the sample by $5 \mathrm{~mm}$. Second, the dilatometer values were recorded every 2 hours $\left(Z_{t}\right)$. The initial number on the dilatometer was recorded as $Z_{0}$. The sample height was $H_{0}$, and the expansion rate $(\delta)$ was calculated as follows:

$$
\delta_{\mathrm{t}}=\frac{Z_{\mathrm{t}}-Z_{0}}{H_{0}}
$$

(5) Leaching Tests. They were conducted on samples for determining the leachability of barium $(\mathrm{Ba})$, copper $(\mathrm{Cu})$, zinc $(\mathrm{Zn})$, chromium $(\mathrm{Cr})$, nickel $(\mathrm{Ni})$, and lead $(\mathrm{Pb})$. The samples cured for 28 days were crushed to less than $9.5 \mathrm{~mm}$ in size. $50 \mathrm{~g}$ of the crushed samples was weighed and placed in a $2 \mathrm{~L}$ Erlenmeyer flask. Then, $1000 \mathrm{~mL}$ of deionized water was added into the flask and the oscillation was adjusted. The oscillator frequency was $110 \pm 10$ beats $/ \mathrm{min}$, and the amplitude was $40 \mathrm{~mm}$. The leachate was performed at room temperature for $18 \mathrm{~h}$, and then the extraction fluid was filtered through a $0.45 \mu \mathrm{m}$ membrane. The content of heavy metals leaching from the samples was analyzed using inductively coupled plasma (ICP) optical emission spectrometry (PekinElmer Model OPTIMA 8000 DV ICP-OES). The leaching results were compared with the concentration limits according to GB 5085.3-2007 [19].

2.2.3. Analytical Methods. The test specimens were prepared into $3 \mathrm{~mm}$ granular samples and then dried at $60 \pm 2^{\circ} \mathrm{C}$ for $6 \mathrm{~h}$ to reduce the effects of the samples' pore structure. The mineral phases of the samples were identified by X-ray diffraction using an ARL 9900 diffractometer with $\mathrm{Cu}$ radiation. The test was operated at $40 \mathrm{kV}$ and $40 \mathrm{~mA}$, with scanning range of $5^{\circ}-85^{\circ}, 2 \theta$. Mercury intrusion porosimetry was performed using a Promaster GT-60 (Quantachrome, USA) to determine both the porosity and pore size distribution. The sample morphologies were determined using JEOL JCM-6510 scanning-electron microscopy with an acceleration voltage of $15 \mathrm{kV}$. Before testing, the samples were coated with gold.

\section{Discussion}

\subsection{Road Performance Evaluation Results}

3.1.1. Compressive Strength Results. The 28-day unconfined compressive strength (UCS) results for the solidified blocks are shown in Figure 3. Generally, the compressive strength increased followed the curing period; the highest strength results were obtained for the P3 (5.890 MPa) and P6 (5.590 MPa) samples, which were cured for 28 days. Upon comparing P3 and P6, it was clear that the OFS binder strength was almost the same as that of ordinary Portland cement. The higher the percentage of PG material, the greater the increase in compressive strength was. For example, the samples incorporating 40\% (P1), 60\% (P2), and 


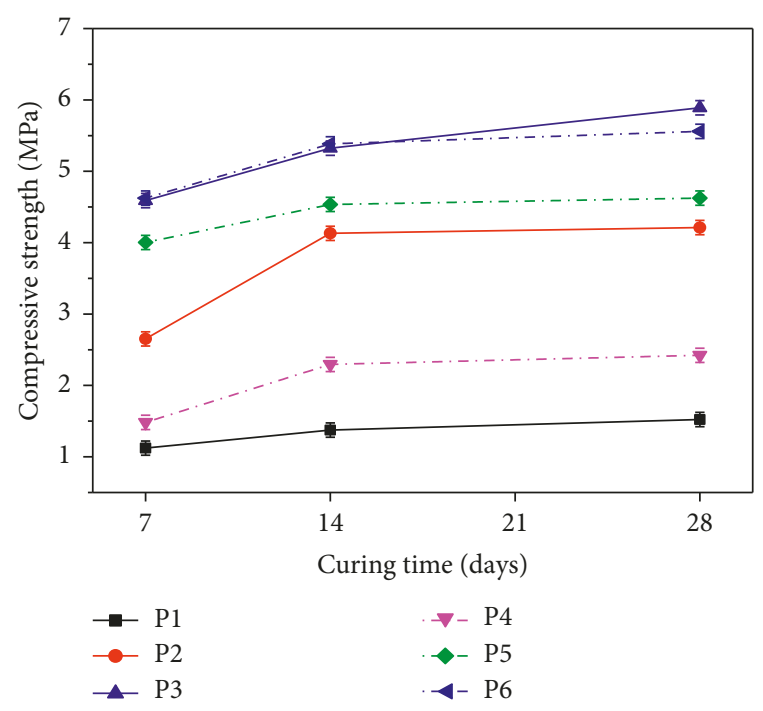

Figure 3: Compressive strength results.

67\% (P3) PG as filler had 7-day compressive strengths of $1.122 \mathrm{MPa}, 2.652 \mathrm{MPa}$, and $4.590 \mathrm{MPa}$, respectively. This growth trend also occurred among the comparison samples (P4, P5, and P6) and can be explained based on filler phenomena. With increasing PG dosage and decreasing OS, the effects of organics on cement hydration in the mixtures was gradually weakened. On the other hand, the PG in the mixtures is an inert material, mainly acting as a filler [20-22]. Additionally, a small amount of PG can react with other binders to produce Aft, which contributes to improving the compressive strength of the samples [23,24]. The interpretation of the UCS results and the waste management criteria was vital. The 7-day UCS results for all samples except P1 met the strength requirements for Grade II and Grade II Highway Subbase (1.5-2 MPa), according to the Specification for Construction Technology of Highway Pavement Base (JTJ 034-2000) [25].

3.1.2. Water Stability Evaluation. The water stability of a solidified body refers to its ability to resist damage and deformation after water saturation. A higher water stability coefficient for a solidified body indicates better water stability. Figure 4 shows that the water stability coefficient of samples decreased with time. However, the water stability coefficient of P5 from 1 day to 7 days remained almost unchanged, with values of $0.92,0.90$, 0.90 , and 0.90 . The best water stability coefficients among the samples were for P3 (0.98) and P6 (0.98) on day 1 . The water stability coefficients for samples that used only Portland cement as a binder were higher than those with OFS binders after 7 days of water immersion. This is because the hydration reaction of Portland cement is significant to the water stability of the solidified body. With more Portland cement, more hydration products are generated, filling the pores of the solidified body and making its structure macroscopically more compact. The results show lower water absorption and a higher water stability coefficient [26].

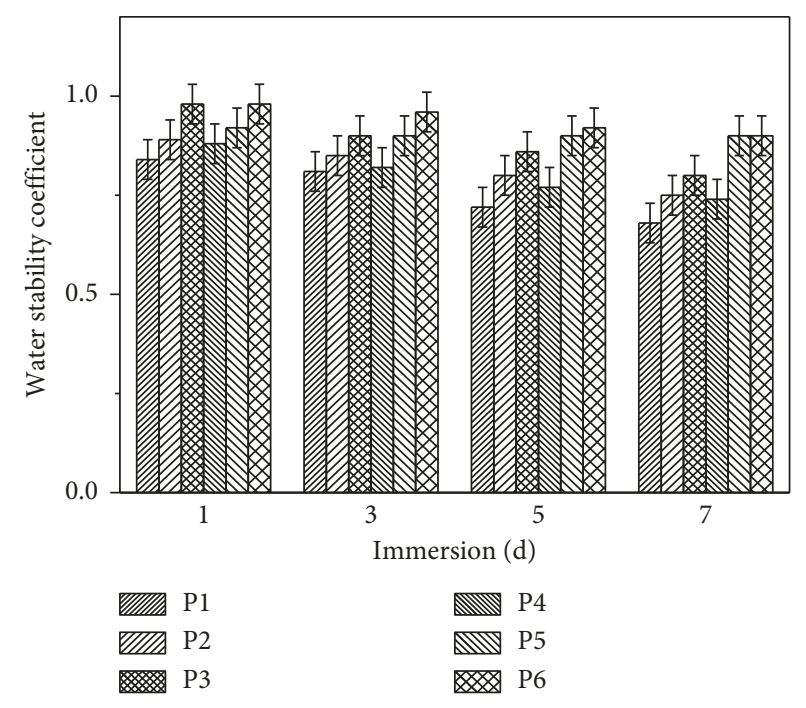

Figure 4: Water stability coefficient results.

3.1.3. Freeze-Thaw Cycle Evaluation. Freeze-thaw resistance is the ability of a solidified body to resist damage and deformation when subjected to freeze-thaw cycles. Figure 5(a) shows the mass loss rate of samples after freeze-thaw cycles. The mass loss rate of all samples increased with the freeze-thaw cycle times. Among the samples, the highest mass loss rate was associated with P1, which reached $12 \%$ after 20 freeze-thaw cycles. The mass loss rate trends for P3 and P6 were relatively stable. Figure 5(b) shows the strength loss rate of samples after freeze-thaw cycles. The strength of the solidified bodies decreased after 20 freeze-thaw cycles; the highest strength loss rate was also associated with $\mathrm{P} 1$, which reached $28 \%$. The strength loss rate change trends for P3 and P6 are relatively stable, with values of $11 \%$ and $12 \%$, respectively. Mass loss and strength loss had the same change trends, partly because of the change of structural stability when the temperature decreased. The water in the solidified body produced expansion stress after the water and ice phase transformations. After several freeze-thaw cycles, the surface of the solidified body exfoliated and cracked, which caused great damage to the solidified body [27]. Second, more hydration products were conducive to the stability of the solidified body. After solidification by using more Portland cement as a binder, the oily sludge with low organic matter content had good freeze-thaw resistance.

3.1.4. Expansion Evaluation. The results of the expansion tests are shown in Figure 6. Clearly, the expansion rate of the solidified body increased with time. The expansion rate of samples increased rapidly during the first few hours. After 12 hours, the expansion rate curves stabilized; the highest expansion rate was for P3, which reached $0.34 \%$. Regardless of the amount of added PG material, the expansion rate of tested samples increased, and the expansion rate decreased as the amount of cement increased. For example, mixtures 


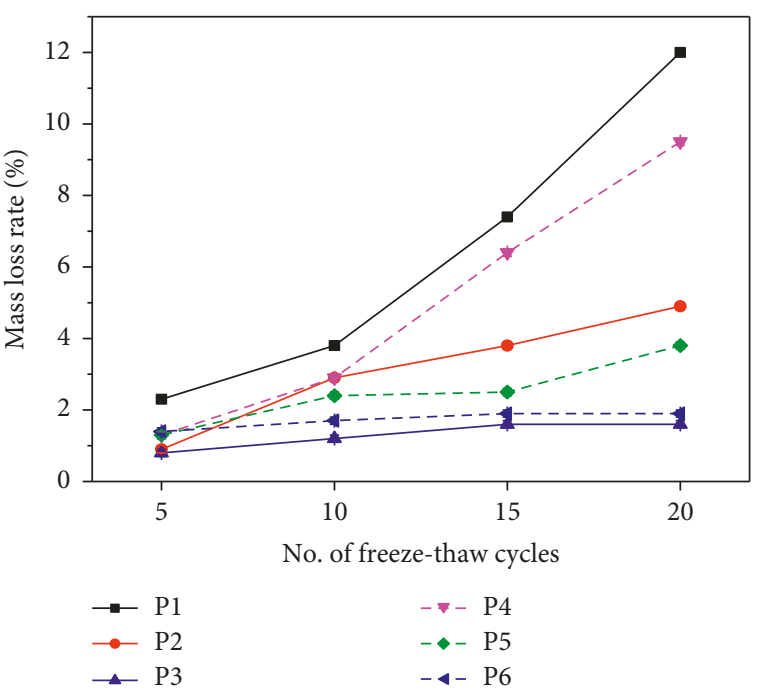

(a)

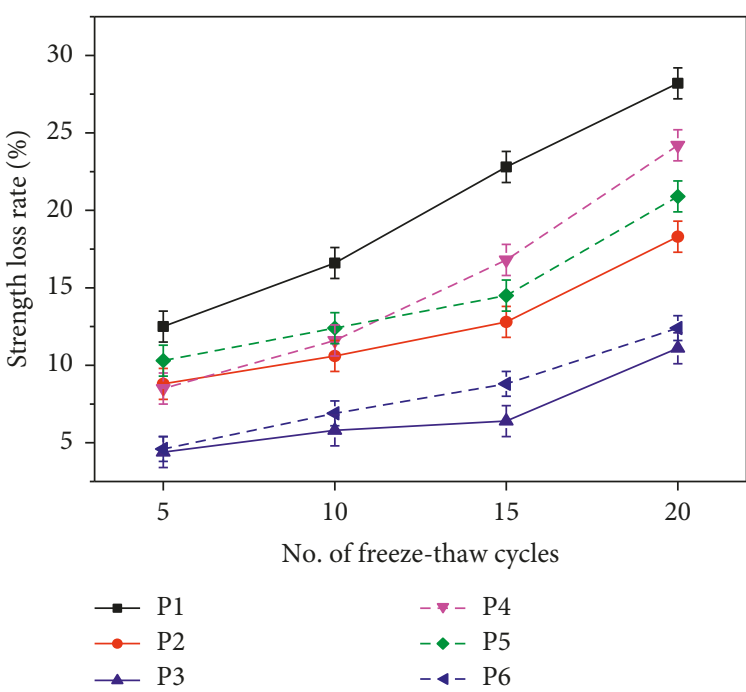

(b)

Figure 5: Mass loss rate (a) and strength loss rate (b) of samples after freeze-thaw cycles.

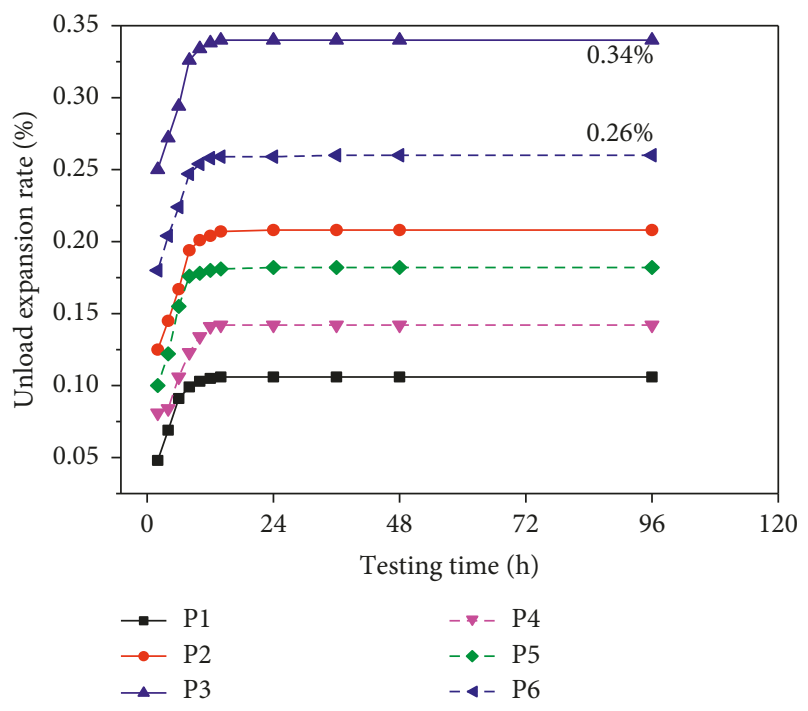

Figure 6: Expansion rate versus time.

that incorporated only Portland cement binders (P4, P5, and P6) exhibited $48 \%, 45 \%$, and $47 \%$ lower expansion rates than those with OFS binders (P1, P2, and P3) after 24 hours, respectively.

In the initial stage, there were few hydrated products in the solidified body, and the structure was less dense; water infiltrated and was absorbed by the unreacted PG material, leading to the rapidly increasing expansion rate. Later, when a large amount of phosphogypsum was present, hydrated calcium aluminate reacted with phosphogypsum to form ettringite [28], resulting in volume expansion of the solidified body.

3.1.5. Leaching Tests. The TCLP method is usually used for identifying hazardous waste. Based on the previous results, the minimum compressive strength of samples incorporating different proportions of PG meet the USEPA limit $(350 \mathrm{KPa}$ for 28 days) for solidified material. Therefore, TCLP tests are carried out to identify the leaching properties of heavy metals. Table 6 shows the results of the leaching tests for the samples. All the tested samples show a reduction in heavy metal leaching compared to that of raw oily sludge. Moreover, the levels are below the detection limits, according to GB 5085.32007. The concentration of heavy metals decreases with the addition of PG. For instance, the leaching concentrations of barium, copper, zinc, chromium, nickel, and lead are found to be $0.174 \mathrm{mg} / \mathrm{L}, 0.084 \mathrm{mg} / \mathrm{L}, 0.114 \mathrm{mg} / \mathrm{L}, 0.032 \mathrm{mg} / \mathrm{L}, 0.078 \mathrm{mg} /$ $\mathrm{L}$, and $0.316 \mathrm{mg} / \mathrm{L}$, respectively, in the P3 mixture. These represent $89 \%, 83 \%, 88 \%, 89 \%, 43 \%$, and $5 \%$ reduction compared with raw oily sludge. Moreover, the concentration of most heavy metals in mixtures P1 to P6 is lower than that in OS. This may be attributed to the detention capacity of PG in the mixtures' microstructure; PG blocks the pores and limits the metal leaching process [29]. In addition, increasing the cement percentage in binders with a constant ratio of PG in the mix did not necessarily reduce heavy metal concentration leaching from the samples. For example, sample P3 had less heavy metal leaching than P6, representing a 32\%, 25\%, 27\%, $27 \%, 31 \%$, and $8 \%$ reduction. The pore structure formation may reduce the heavy metal release from the mixtures [30].

3.2. XRD Analysis. Figure 7 shows the $\mathrm{X}$-ray diffraction patterns of the samples. The mineralogical compositions of all selected samples contained phases of photogypsum $\left(\mathrm{Ca}_{2} \mathrm{SO}_{4} \cdot 2 \mathrm{H}_{2} \mathrm{O}\right.$, PDF \# 33-0311), ettringite (AFt, 3CaO. $\mathrm{Al}_{2} \mathrm{O}_{3} \cdot 3 \mathrm{CaSO}_{4} \cdot 32 \mathrm{H}_{2} \mathrm{O}$, PDF \# 41-1451), brushite $\left(\mathrm{CaPO}_{3}\right.$ $(\mathrm{OH}) \cdot 2 \mathrm{H}_{2} \mathrm{O}$, PDF \# 11-293), calcite $\left(\mathrm{CaCO}_{3}, \mathrm{PDF}\right.$ \# 760606), and little quartz $\left(\mathrm{SiO}_{2}, \mathrm{PDF} \# 5-490\right)$. The peaks of photogypsum phase occurred between $10^{\circ}$ and $15^{\circ} 2 \theta$; the ettringite phase between $20^{\circ}$ and $25^{\circ}$ in P3 and P6 were higher than that in $\mathrm{P} 1$ and $\mathrm{P} 2$, which indicates that unreacted PG contributes to the crystalline components of 
TABLE 6: Sample leaching test results.

\begin{tabular}{lccccc}
\hline Sample & $\mathrm{Ba}(\mathrm{mg} / \mathrm{L})$ & $\mathrm{Cu}(\mathrm{mg} / \mathrm{L})$ & $\mathrm{Zn}(\mathrm{mg} / \mathrm{L})$ & $\mathrm{Cr}(\mathrm{mg} / \mathrm{L})$ & $\mathrm{Ni}(\mathrm{mg} / \mathrm{L})$ \\
\hline P1 & 0.921 & 0.210 & 0.235 & 0.067 & 0.214 \\
P2 & 0.522 & 0.154 & 0.117 & 0.035 & 0.124 \\
P3 & 0.174 & 0.084 & 0.083 & 0.032 & 0.078 \\
P4 & 1.140 & 0.321 & 0.287 & 0.098 & 0.188 \\
P5 & 0.535 & 0.132 & 0.142 & 0.055 & 0.152 \\
P6 & 0.255 & 0.112 & 0.114 & 0.044 & 0.113 \\
Limits & 100 & 100 & 100 & 5 & 5 \\
\hline
\end{tabular}

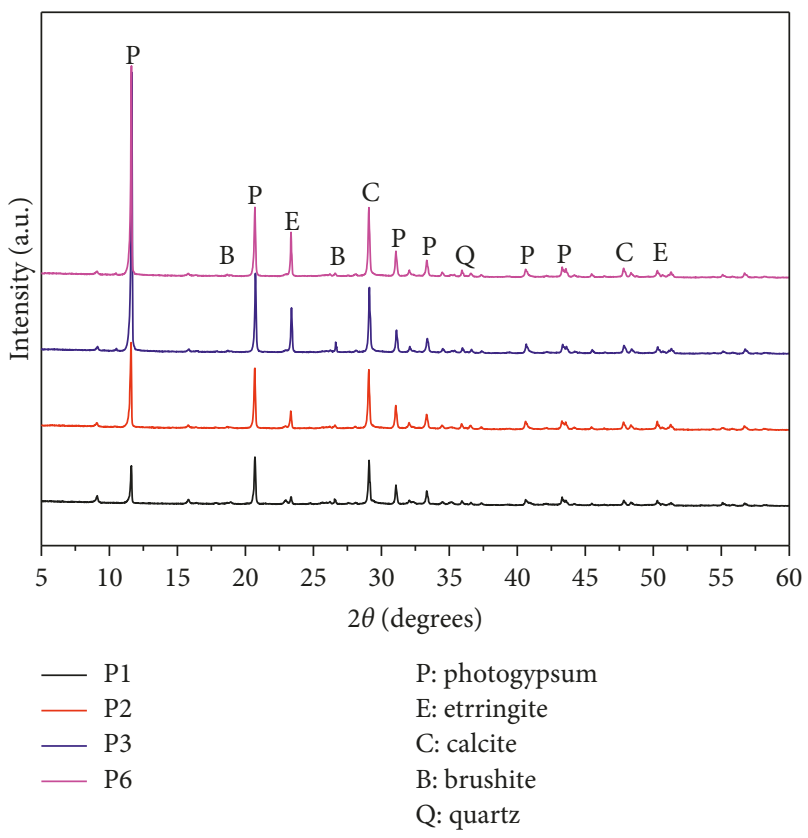

FIGURE 7: XRD patterns of solidified samples.

ettringite. These results agree with previous compressive strength analysis. The formation of hydration products ettringite and calcium carbonate is beneficial to improve the compressive strength, freeze-thaw resistance, and water stability of the solidified body [31, 32].

3.3. Scanning Electron Microscopy. The SEM results of the mixtures incorporating different proportions of $P G$ are shown in Figure 8. The flat construct of unreacted PG (irregular and lamp-like) is found in all SEM images. The P3 sample (Figure 8(a)) presents typical hydration products, such as ettringite (fiber-like crystals) and calcite (gel-like flocks) on the surface and interior of the mixtures. As shown in Figure 8(b), the crystals are aggregated and connected to each other, which surround the PG crystals and form a homogeneous network $[33,34]$. It agrees with the road performance evaluation results in Section 3.2. Moreover, the pores in the P3 sample (Figure $8(\mathrm{c})$ ) are filled by hydration products, which work to reduce the size of the pores. However, there are also more microcracks (approximately $5 \mu \mathrm{m}$ ) appearing in the P3 sample compared with P6 sample (Figure $8(\mathrm{~d})$ ). This is probably because the weak, flat PG particles act as failure points. The inside contraction stress and formation of ettringite cause volume expansion of the solidified body, and the structure of the solidified body becomes denser [35]. The SEM results of the samples (P3 and P6) agree with the expansion evaluation results. P3 sample has a higher expansion coefficient than P6.

3.4. Pore Structure Analysis. The pores in cement-based materials are divided into two pore systems: gel pores $(10 \mathrm{~nm} \leq R \leq 100 \mathrm{~nm})$ and capillary pores $(100 \mathrm{~nm} \leq R \leq$ $1000 \mathrm{~nm}$ ) [36]. The gel pores are formed within the formation of the cement hydration products; capillary pores refer to the remaining spaces not filled by the hydration products. Figure 9 illustrates the pore size and porosity distribution of the samples. The pores in all samples are distributed distinctly differently in the 100 to $1000 \mathrm{~nm} \mathrm{di-}$ ameter range, which corresponds to the gel pores and the capillary pores. For the samples, extending the PG dosage remarkably decreases the pore size and porosity. This is caused by the gel filling effect as the cement hydration proceeds [37]. This phenomenon is consistent with the previous SEM results. Moreover, the sample porosity in the 100 to $1000 \mathrm{~nm}$ range decreases gradually. This is because the pore structure provides an indication of the degree of interconnection among the pores, compressive strength, freeze-thaw resistance, and water stability [38, 39]. The presence of PG might influence the microstructure of the mixture paste, including the critical pore diameter, along with the connectivity of the capillary pores, due to filler. The PG materials contribute to a finer pore structure, which in turn agrees with the enhancement of road performance. It is also interesting that the pores of sample P3 are concentrated from $1000 \mathrm{~nm}$ to $10000 \mathrm{~nm}$ in Figure 8(c), less than that of the P6 sample. This phenomenon agrees with the results of previous leaching tests, which reflect a reduction of heavy metals in the leachate of P3 compared with P6. The free water in the solidified body that contained larger pores became available for evaporation and easily found a path to the surrounding environment, leading to the increased concentration of heavy metals. The pores in the solidified body became larger, which released more of the harmful substances.

\section{Conclusion}

The effects of PG materials applied to oily sludge solidification with binders (OFS) including OPC, FA, and SF were studied. The utilization of PG as a novel stabilizer was developed and tested for S/S of oily sludge. 

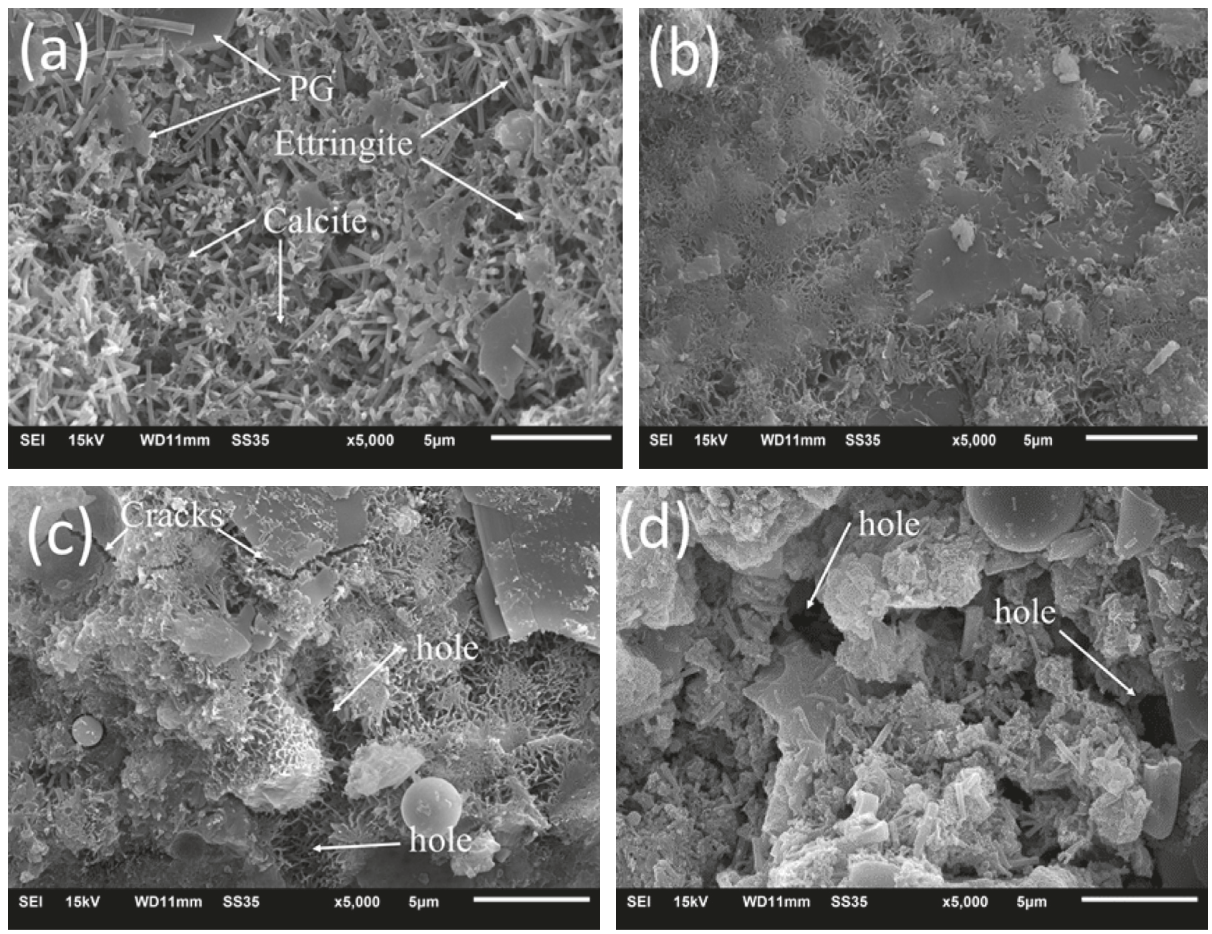

FIGURE 8: SEM images of mixtures incorporating different proportions of PG: (a-c) P3 and (d) P6.

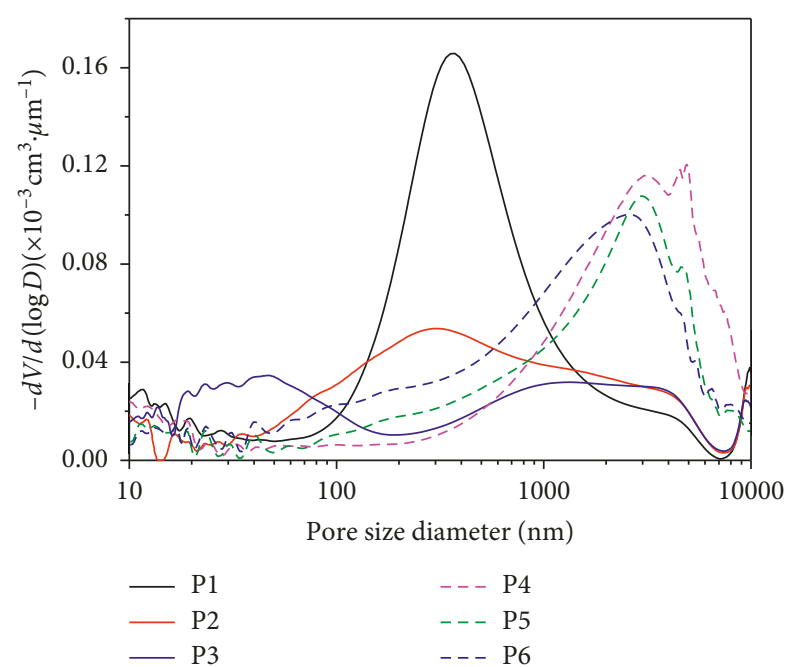

(a)

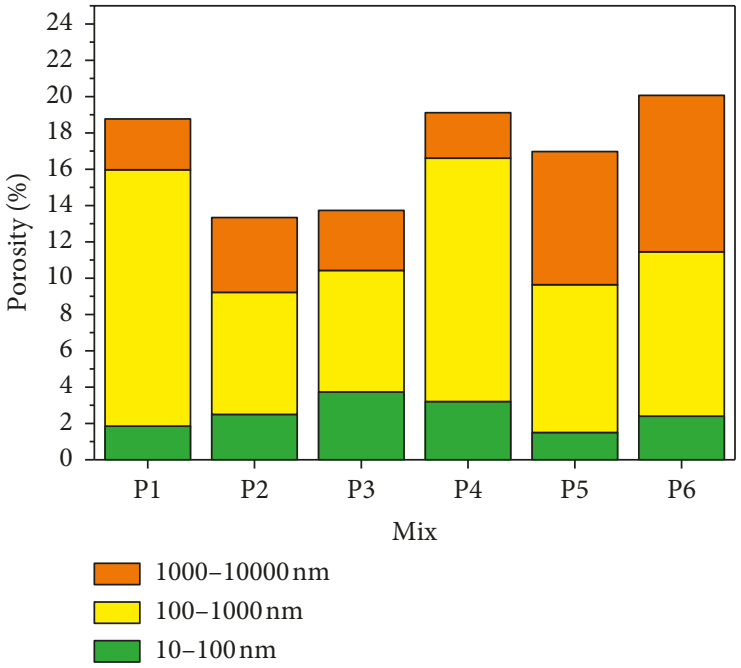

(b)

Figure 9: Pore size (a) and porosity distribution (b) of the samples.

(1) The experimental results indicated that the mixtures incorporating different proportions of PG had a higher compressive strength and met the limits for a Grade II Highway Subbase (1.5-2 MPa) for a solidified body used as roadbed material according to the Specification for Construction Technology of Highway Pavement Base (JTJ 034-2000). Second, the solidified body used as a road base material had sufficient strength and good water stability performance, freeze-thaw resistance, and volumetric stability performance. Moreover, leaching tests showed a high percentage reduction of heavy metals in the mixtures; the heavy metal concentrations were below the detection limits.

(2) Typical hydration products were found in the samples, such as the photogypsum phase, brushite phase, ettringite phase, and calcite phase. The porosity decrease in the 100 to $1000 \mathrm{~nm}$ range entailed a higher capillary tension that developed in the capillary pores to increase the compressive strength of the samples. Lastly, the microstructure analysis of SEM not only clearly identified the hydration products but also confirmed previous results. The addition of PG decreased the concentration and 
toxicity of the heavy metals released from the oily sludge, indicating that employing $\mathrm{PG}$ as stabilizer material is a significant alternative to the landfill disposal of oily sludge.

(3) After solidification using phosphogypsum-based cementitious materials, the oily sludge had excellent road performance, including sufficient strength and good water stability performance, freeze-thaw resistance, and volumetric stability performance, which confirms that an oily sludge can be used as a roadbed material to solidify the body.

\section{Data Availability}

The data used to support the findings of this study are included within the article.

\section{Conflicts of Interest}

The authors declare that they have no conflicts of interest.

\section{Acknowledgments}

This work was funded by the Priority Academic Program Development of Jiangsu Higher Education Institutions (PAPD), China.

\section{References}

[1] L. J. Da Silva, F. C. Alves, and F. P. de França, "A review of the technological solutions for the treatment of oily sludges from petroleum refineries," Waste Management \& Research, vol. 30, no. 10, pp. 1016-1030, 2012.

[2] G. Hu, J. Li, and G. Zeng, "Recent development in the treatment of oily sludge from petroleum industry: a review," Journal of Hazardous Materials, vol. 261, pp. 470-490, 2013.

[3] M. Li, H. Ou, Z. Li, T. Gu, H. Liu, and X. Guo, "Contamination of cement slurries with diesel-based drilling fluids in a shale gas well," Journal of Natural Gas Science and Engineering, vol. 27, pp. 1312-1320, 2015.

[4] S.-J. Wang, Z.-G. Yan, G.-L. Guo, G.-L. Lu, Q.-H. Wang, and F.-S. Li, "Ecotoxicity assessment of aged petroleum sludge using a suite of effects-based end points in earthworm Eisenia fetida," Environmental Monitoring and Assessment, vol. 169, no. 1-4, pp. 417-428, 2010.

[5] S. A. Leonard and J. A. Stegemann, "Stabilization/ solidification of petroleum drill cuttings: leaching studies," Journal of Hazardous Materials, vol. 174, no. 1-3, pp. 484-491, 2010.

[6] B. Vacenovska, V. Cerny, R. Drochytka et al., "Verification of the possibility of solidification product made of neutralization sludge use in the building industry," Procedia Engineering, vol. 57, pp. 1192-1197, 2013.

[7] M. Mohebbi, S. Gitipour, and E. Madadian, "Solidification/ stabilization of cresol-contaminated soil: mechanical and leaching behavior," Soil and Sediment Contamination: An International Journal, vol. 22, no. 7, pp. 783-799, 2013.

[8] L. Mater, R. Sperb, L. Madureira, A. Rosin, A. Correa, and C. Radetski, "Proposal of a sequential treatment methodology for the safe reuse of oil sludge-contaminated soil," Journal of Hazardous Materials, vol. 136, no. 3, pp. 967-971, 2006.
[9] R. B. Kogbara, A. Al-Tabbaa, and J. A. Stegemann, "Comparisons of operating envelopes for contaminated soil stabilised/solidified with different cementitious binders," Environmental Science and Pollution Research, vol. 21, no. 5, pp. 3395-3414, 2014.

[10] J. W. Ding, S. H. Zhang, and Z. S. Liu, "Experimental study of solidification of dredged clays with high water content by adding cement and phosphogypsum synchronously," Rock and Soil Mechanics, vol. 31, pp. 2817-2822, 2010.

[11] S. M. Rao and K. Asha, "Role of fly ash pozzolanic reactions in controlling fluoride release from phosphogypsum," Journal of Materials in Civil Engineering, vol. 25, no. 8, pp. 999-1005, 2013.

[12] R. Li, S. Xia, and J. Zhu, "The experimental investigation of drilling waste slurries solidification with phosphogypsum and cinder ash," Chemical Engineering of Oil and Gas, vol. 34, pp. 225-227, 2005.

[13] International Standard ISO 9029-1990, Crude PetroleumDetermination of Water-Distillation Method, International Organization for Standardization, Geneva, Switzerland, 1990.

[14] ASTM D1744, Standard Test Method for Determination of Water in Liquid Petroleum Products by Karl Fischer Reagent, ASTM International, West Conshohocken, PA, USA, 1992.

[15] Chinese Standard JTG E51-2009, Test Procedure for Inorganic Binders for Highway Engineering, Chinese Standard, Beijing, China, 2009.

[16] ASTM D2166, Standard Test Method for Unconfined Compressive Strength of Cohesive Soil, American Society for Testing and Materials, West Conshohocken, PA, USA, 1998.

[17] Chinese Standard JTJ 051-1993, Highway Engineering Test Procedure, Chinese Standard, Beijing, China, 1993.

[18] Chinese Standard GBT 50123-1999, Geotechnical Test Method Standard, Chinese Standard, Beijing, China, 1999.

[19] Chinese Standard GB 5085.3-2007, Identification Standards for Hazardous Wastes-Identification for Extraction Toxicity, Chinese Standard, Beijing, China, 2007.

[20] M. Cyr, P. Lawrence, and E. Ringot, "Efficiency of mineral admixtures in mortars: quantification of the physical and chemical effects of fine admixtures in relation with compressive strength," Cement and Concrete Research, vol. 36, no. 2, pp. 264-277, 2006.

[21] A. Velayati, B. Tokhmechi, H. Soltanian, and E. Kazemzadeh, "Cement slurry optimization and assessment of additives according to a proposed plan," Journal of Natural Gas Science and Engineering, vol. 23, pp. 165-170, 2015.

[22] L. Liu, Y. Zhang, and K. Tan, "Cementitious binder of phosphogypsum and other materials," Advances in Cement Research, vol. 27, no. 10, pp. 567-570, 2015.

[23] M. Aboutabikh, A. M. Soliman, and M. H. El Naggar, "Properties of cementitious material incorporating treated oil sands drill cuttings waste," Construction and Building Materials, vol. 111, pp. 751-757, 2016.

[24] M. Jianli, Z. Youcai, W. Jinmei, and W. Li, "Effect of magnesium oxychloride cement on stabilization/solidification of sewage sludge," Construction and Building Materials, vol. 24, no. 1, pp. 79-83, 2010.

[25] Chinese Standard JTJ 034-2000, Technical Specification for Road Pavement Base Construction, Chinese Standard, Beijing, China, 2000.

[26] M. C. C. Canut, V. M. F. Jacomino, K. Bråtveit, A. M. Gomes, and M. I. Yoshida, "Microstructural analyses of phosphogypsum generated by Brazilian fertilizer industries," Materials Characterization, vol. 59, no. 4, pp. 365-373, 2008. 
[27] A. Roy, H. C. Eaton, F. K. Cartledge, and M. E. Tittlebaum, "Solidification/stabilization of hazardous waste: evidence of physical encapsulation," Environmental Science \& Technology, vol. 26, no. 7, pp. 1349-1353, 1992.

[28] Z. Gu, S. Hua, W. Zhao, S. Li, Z. Gao, and H. Shan, "Using alkali-activated cementitious materials to solidify high organic matter content dredged sludge as roadbed material," $A d$ vances in Civil Engineering, vol. 2018, Article ID 2152949, 10 pages, 2018.

[29] Z. C. Kadirova, M. Hojamberdiev, L. L. Bo, R. Hojiyev, and K. Okada, "Ion uptake properties of low cost inorganic sorption materials in the $\mathrm{CaO}-\mathrm{Al}_{2} \mathrm{O}_{3}-\mathrm{SiO}_{2}$ system prepared from phosphogypsum and kaolin," Journal of Cleaner Production, vol. 83, pp. 486-490, 2014.

[30] M. Katsioti, N. Katsiotis, G. Rouni, D. Bakirtzis, and M. Loizidou, "The effect of bentonite/cement mortar for the stabilization/solidification of sewage sludge containing heavy metals," Cement and Concrete Composites, vol. 30, no. 10, pp. 1013-1019, 2008.

[31] O. Malliou, M. Katsioti, A. Georgiadis, and A. Katsiri, "Properties of stabilized/solidified admixtures of cement and sewage sludge," Cement and Concrete Composites, vol. 29, no. 1, pp. 55-61, 2007.

[32] EN196-1, Methods of Testing Cements-Determination of Compressive Strength, BSI Standards Limited 2016, London, UK, 2016.

[33] J. L. Provis, P. Duxson, and J. S. J. Van Deventer, "The role of particle technology in developing sustainable construction materials," Advanced Powder Technology, vol. 21, no. 1, pp. 2-7, 2010.

[34] D. Dermatas, "Ettringite-induced swelling in soils: state-ofthe-art," Applied Mechanics Reviews, vol. 48, no. 10, pp. 659-673, 1995.

[35] L. Cui and J. H. Cahyadi, "Permeability and pore structure of OPC paste," Cement and Concrete Research, vol. 31, no. 2, pp. 277-282, 2001.

[36] S. Hua, K. Wang, and X. Yao, "Developing high performance phosphogypsum-based cementitious materials for oil-well cementing through a step-by-step optimization method," Cement and Concrete Composites, vol. 72, pp. 299-308, 2016.

[37] J. L. Provis, R. J. Myers, C. E. White, V. Rose, and J. S. J. van Deventer, "X-ray microtomography shows pore structure and tortuosity in alkali-activated binders," Cement and Concrete Research, vol. 42, no. 6, pp. 855-864, 2012.

[38] T. Yang, H. Zhu, and Z. Zhang, "Influence of fly ash on the pore structure and shrinkage characteristics of metakaolinbased geopolymer pastes and mortars," Construction and Building Materials, vol. 153, pp. 284-293, 2017.

[39] M. G. Richardson, Fundamentals of Durable Reinforced Concrete, Modern Concrete Technology, New York, NY, USA, 2002. 


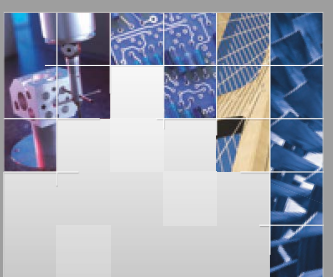

\section{Enfincering}
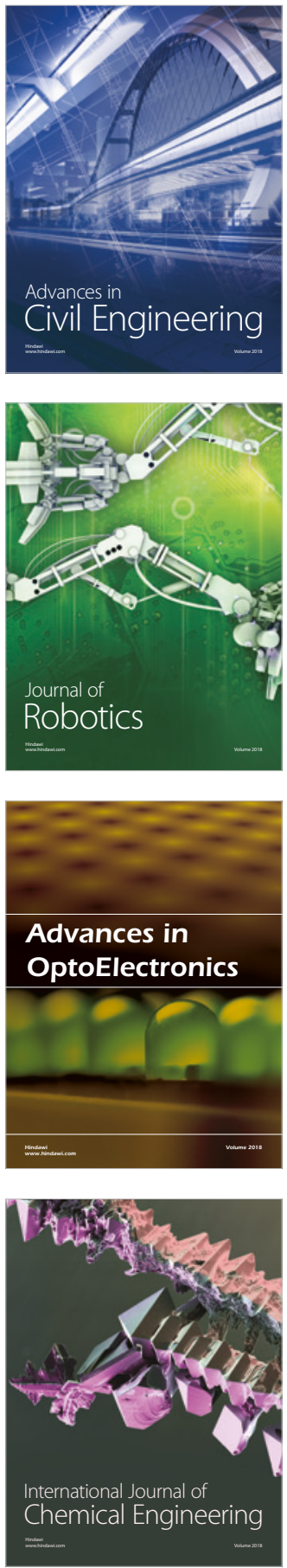

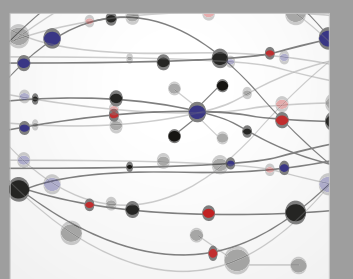

\section{Rotating \\ Machinery}

The Scientific World Journal

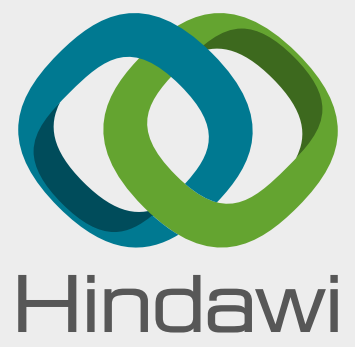

Submit your manuscripts at

www.hindawi.com
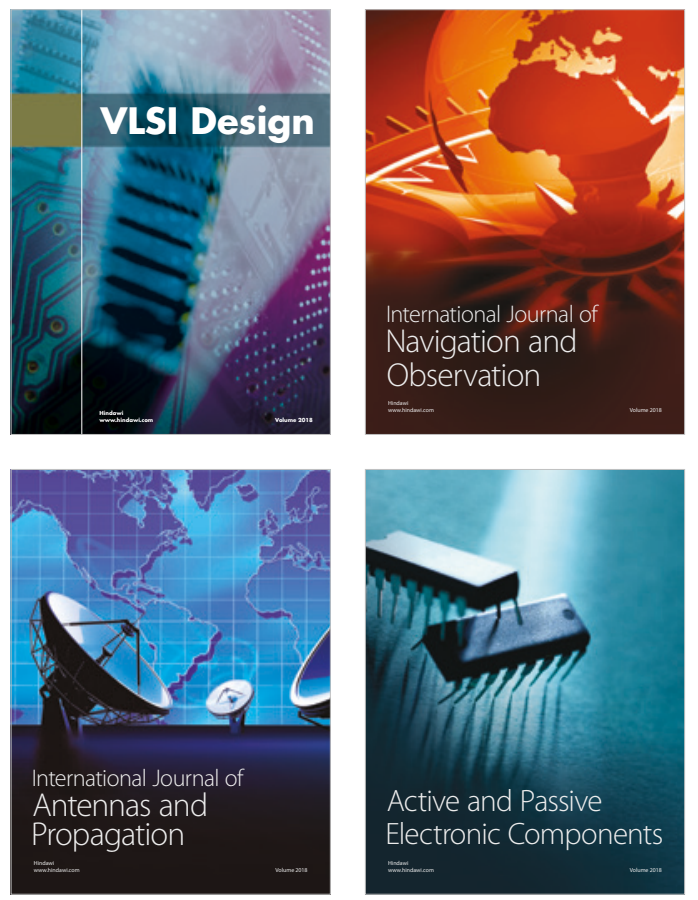
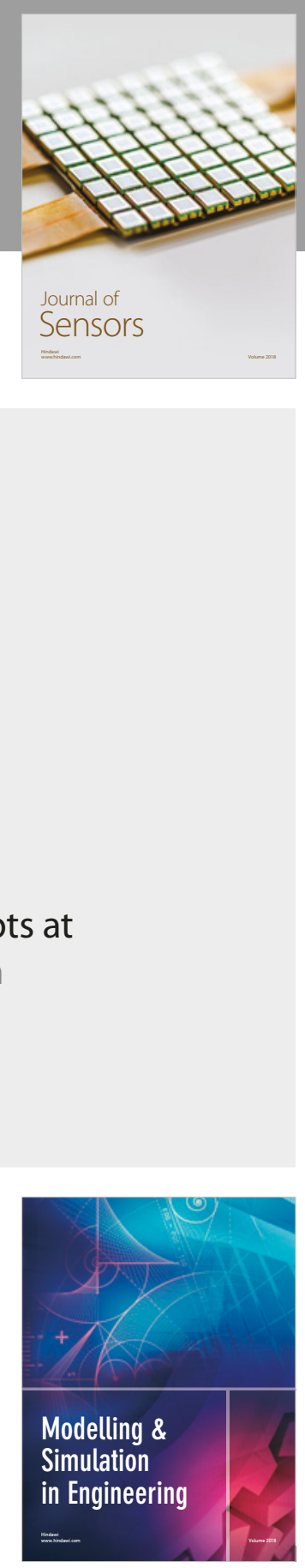

\section{Advances \\ Multimedia}
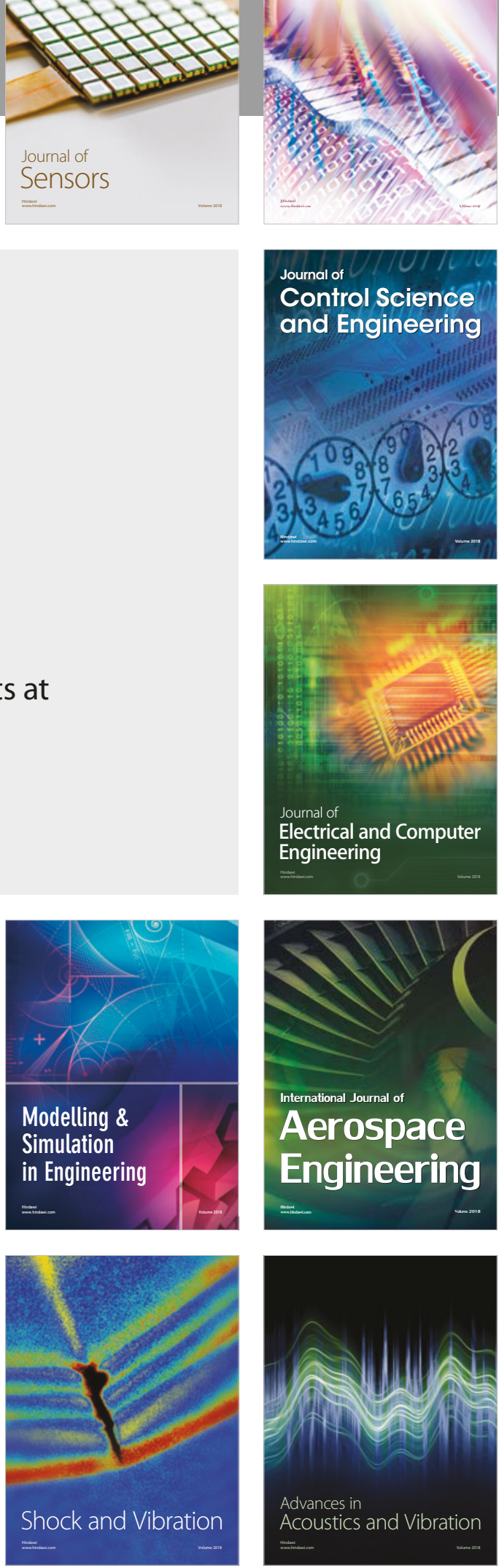